\title{
Elevated luteinizing hormone despite normal testosterone levels in older men-natural history, risk factors and clinical features
}

DOI:

10.1111/cen.13524

\section{Document Version}

Accepted author manuscript

Link to publication record in Manchester Research Explorer

Citation for published version (APA):

Eendebak, R. J. A. H., Ahern, T., Swiecicka, A., Pye, S. R., O'Neill, T., Bartfai, G., Forti, G., Giwercman, A., Han, T. S., Slowikowska-Hilczer, J., Lean, M., Maggi, M., Punab, M., Pendleton, N., Keevil, B., Vanderschueren, D., Rutter, M., Tampubolon, G., Goodacre, R., ... EMAS Group (2018). Elevated luteinizing hormone despite normal testosterone levels in older men-natural history, risk factors and clinical features. Clinical Endocrinology, 88(3), 479-490. https://doi.org/10.1111/cen.13524

Published in:

Clinical Endocrinology

\section{Citing this paper}

Please note that where the full-text provided on Manchester Research Explorer is the Author Accepted Manuscript or Proof version this may differ from the final Published version. If citing, it is advised that you check and use the publisher's definitive version.

\section{General rights}

Copyright and moral rights for the publications made accessible in the Research Explorer are retained by the authors and/or other copyright owners and it is a condition of accessing publications that users recognise and abide by the legal requirements associated with these rights.

\section{Takedown policy}

If you believe that this document breaches copyright please refer to the University of Manchester's Takedown Procedures [http://man.ac.uk/04Y6Bo] or contact uml.scholarlycommunications@manchester.ac.uk providing relevant details, so we can investigate your claim.

\section{OPEN ACCESS}


DR TOMAS AHERN (Orcid ID : 0000-0001-8309-7853)

DR BRIAN KEEVIL (Orcid ID : 0000-0002-0684-9318)

Article type : 1 Original Article - UK, Europe

\section{Elevated Luteinising Hormone despite Normal Testosterone Levels in older Men}

- Natural History, Risk Factors, and Clinical Features

Short Running Title: Elevated LH in Ageing Men

Robert J.A.H. Eendebak ${ }^{1^{*}}$, Tomas Ahern ${ }^{1^{*}}$, Agnieszka Swiecicka ${ }^{1}$, Stephen R. Pye ${ }^{2}$, Terence W. O'Neill ${ }^{2}$, Gyorgy Bartfai ${ }^{3}$, Felipe F. Casanueva ${ }^{4}$, Mario Maggi ${ }^{5}$, Gianni Forti ${ }^{5}$, Aleksander Giwercman ${ }^{6}$, Thang S. Han ${ }^{7}$, Jolanta Słowikowska-Hilczer ${ }^{8}$, Michael E. J. Lean ${ }^{9}$, Margus Punab ${ }^{10}$, Neil Pendleton ${ }^{11}$, Brian G. Keevil ${ }^{12}$, Dirk Vanderschueren ${ }^{13}$, Martin K. Rutter ${ }^{14}$, Gindo Tampubolon ${ }^{15}$, Royston Goodacre ${ }^{16}$, Ilpo T. Huhtaniemi ${ }^{17^{\star *}}$ and Frederick C.W. Wu ${ }^{1 * \star}$ for the EMAS Group

${ }^{1}$ University of Manchester, Manchester Academic Health Sciences Centre, Faculty of Medical and Human Sciences, Institute of Human Development, Centre for Endocrinology and Diabetes, Andrology Research Unit, Manchester, United Kingdom

${ }^{2}$ Arthritis Research UK Centre for Epidemiology, Division of Musculoskeletal \& Dermatological Sciences, Faculty of Biology, Medicine and Health, University of Manchester and NIHR Manchester Musculoskeletal Biomedical Research Unit, Central Manchester NHS Foundation Trust, Manchester, United Kingdom

${ }^{3}$ Department of Obstetrics, Gynaecology and Andrology, Albert Szent-György Medical University, Szeged, Hungary

This article has been accepted for publication and undergone full peer review but has not been through the copyediting, typesetting, pagination and proofreading process, which may lead to differences between this version and the Version of Record. Please cite this article as doi: $10.1111 /$ cen. 13524

This article is protected by copyright. All rights reserved. 
${ }^{4}$ Department of Medicine, Santiago de Compostela University, Complejo Hospitalario Universitario de Santiago (CHUS); CIBER de Fisiopatología Obesidad y Nutricion (CB06/03), Instituto Salud Carlos III; Santiago de Compostela, Spain

${ }^{5}$ Sexual Medicine and Andrology Unit, Department of Experimental and Clinical Biomedical Sciences "Mario Serio", University of Florence, Florence, Italy

${ }^{6}$ Department of Translational Medicine, Lund University, Malmö, Sweden

${ }^{7}$ Institute of Cardiovascular Research, Royal Holloway University of London (ICR2UL) and Ashford and St Peter's NHS Foundation Trust, Egham, Surrey, United Kingdom ${ }^{8}$ Department of Andrology and Reproductive Endocrinology, Medical University of Łódź, Łódź, Poland

${ }^{9}$ Department of Human Nutrition, University of Glasgow, Glasgow, United Kingdom

${ }^{10}$ Andrology Unit, United Laboratories of Tartu University Clinics, Tartu, Estonia

${ }^{11}$ Centre for Clinical and Cognitive Neuroscience, University of Manchester, Manchester, United Kingdom

${ }^{12}$ Department of Clinical Biochemistry, University Hospital of South Manchester, Manchester, United Kingdom

${ }^{13}$ Department of Andrology and Endocrinology, Katholieke Universiteit Leuven, Leuven, Belgium

${ }^{14}$ Manchester Diabetes Centre, Central Manchester University Hospitals NHS Foundation Trust, Manchester Academic Health Science, Manchester, United Kingdom

${ }^{15}$ Cathie Marsh Institute for Social Research. Faculty of Humanities, University of Manchester, Manchester, United Kingdom

${ }^{16}$ School of Chemistry, Manchester Institute for Biotechnology, University of Manchester, Manchester, United Kingdom

${ }^{17}$ Department of Surgery and Cancer, Institute of Reproductive and Developmental Biology, Imperial College London, Hammersmith Campus, London, United Kingdom and Department of Physiology, Institute of Biomedicine, University of Turku, Finland

This article is protected by copyright. All rights reserved. 


\section{Acknowledgements}

The European Male Ageing Study is funded by the Commission of the European

Communities Fifth Framework Programme "Quality of Life and Management of Living Resources" Grant QLK6-CT-2001-00258 and facilitated by the Manchester Academic Health Sciences Centre and the NIHR Greater Manchester: Clinical Research Network. Additional support was also provided by Arthritis Research United Kingdom and the National Institute for Health Research and the Manchester Academic Health Sciences Centre.

The Principal Investigator of EMAS is Professor Frederick Wu, MD; Andrology Research Unit, University of Manchester, Manchester, United Kingdom. The authors wish to thank the men who participated in the eight countries, the research/nursing staff in the eight centres: C Pott (Manchester), E Wouters (Leuven), M Nilsson (Malmö), M del Mar Fernandez (Santiago de Compostela), M Jedrzejowska (Łódź), H-M Tabo (Tartu), A Heredi (Szeged) for their data collection, and C Moseley (Manchester) for data entry and project co-ordination. Dr. D Vanderschueren is a senior clinical investigator supported by the Clinical Research Fund of the University Hospitals Leuven, Belgium. Robert J.A.H. Eendebak is supported by a Biotechnology and Biological Sciences Research Council - Doctoral Training Partnership (BBSRC-DTP) PhD fellowship and is grateful for support received from the Fundatie van de Vrijvrouwe van Renswoude and Scholten-Cordes scholarship foundations.

Keywords: luteinizing hormone; testosterone; ageing; hypogonadism; physical function

Corresponding author's contact details

Dr Tomás Ahern, MB BCh BAO

Andrology Research Unit, Centre for Endocrinology and Diabetes

Institute of Human Development, Faculty of Medical and Human Sciences

University of Manchester

This article is protected by copyright. All rights reserved. 
Old St Mary's Building, Hathersage Road

Manchester M13 9WL

United Kingdom

Phone: +44161276 6295

Fax: +44161276 6363

E-mail: tomasbahern@physicians.ie.

${ }^{*}$ Robert J.A.H. Eendebak and Tomás Ahern should be considered joint first author

** Ilpo T Huhtaniemi and Frederick C.W. Wu should be considered joint senior author

\section{Abstract \\ Objective}

Elevated LH with normal testosterone $(\mathrm{T})$ suggests compensated dysregulation of the gonadal axis. We describe the natural history, risk factors and clinical parameters associated with the development of high $\mathrm{LH}(\mathrm{HLH}, \mathrm{LH}>9.4 \mathrm{U} / \mathrm{L})$ in ageing men with normal $\mathrm{T}(\mathrm{T} \geq 10.5$ $\mathrm{nmol} / \mathrm{L})$.

\section{Design, Patients and Measurements}

We conducted a 4.3 year prospective observational study of 3,369 community-dwelling European men aged 40-79 years. Participants were classified as: incident (i) HLH ( $n=101$, 5.2\%); persistent (p) HLH ( $n=128,6.6 \%)$; reverted $(r) H L H(n=46,2.4 \%)$; or persistent normal LH (pNLH, $\mathrm{n}=1667,85.8 \%)$. Potential predictors and changes in clinical features associated with iHLH and rHLH were analysed using regression models.

Results

Age $>70$ years $(\mathrm{OR}=4.12[2.07-8.20])$, diabetes $(\mathrm{OR}=2.86[1.42-5.77])$, chronic pain $(\mathrm{OR}=2.53[1.34-4.77])$, pre-degree education $(\mathrm{OR}=1.79[1.01-3.20])$ and low physical activity (PASE $\leq 78, \mathrm{OR}=2.37[1.24-4.50])$ predicted development of $\mathrm{HLH}$. Younger age (40-49 years, $\mathrm{OR}=8.14[1.35-49.13])$ and non-smoking $(\mathrm{OR}=5.39[1.48-19.65])$ predicted recovery from HLH. Men with iHLH developed erectile dysfunction, poor health, cardiovascular disease (CVD) and cancer more frequently than pNLH men. In pHLH men, co-morbidities, including 
CVD, developed more frequently, and cognitive and physical function deteriorated more, than in pNLH men. Men with HLH developed primary hypogonadism more frequently $(\mathrm{OR}=15.97[5.85-43.60])$ than NLH men. Men with rHLH experienced a small rise in BMI. Conclusions

Elevation of $\mathrm{LH}$ with normal $\mathrm{T}$ is predicted by multiple factors, reverts frequently and is not associated with unequivocal evidence of androgen deficiency. High $\mathrm{LH}$ is a biomarker for deteriorating health in aged men who tend to develop primary hypogonadism.

\section{Introduction}

Ageing is associated with myriad alterations in endocrine functions, ${ }^{1}$ some of which may contribute to a decline in health and quality of later life. Elevated LH with normal testosterone $(\mathrm{T})$ is encountered commonly in ageing men $^{2}$ and may present a diagnostic and therapeutic dilemma to the practicing clinician. High LH may signify the onset of dysregulation in the hypothalamic-pituitary-testicular (HPT) axis, whereby compensatory increase in luteinising hormone $(\mathrm{LH})$ is required to mobilise the Leydig cell steroidogenic reserves to maintain normal T production. We have suggested that this may represent a state of 'compensated' hypogonadism, ${ }^{2}$ where high LH concentration in the face of normal T (HLH) marks an intermediate stage before transitioning towards overt primary hypogonadism (PHG) when testicular reserve eventually becomes exhausted. The rate of transition (progression and reversal) from normal $\mathrm{LH}(\mathrm{NLH})$ to $\mathrm{HLH}$ and the factors that influence its development in ageing men are important issues that are yet to be explored in prospective studies. Whether men with HLH experience symptoms, functional deficits or morbidity, without the development of a low $\mathrm{T}$, is unclear. In particular, the proportion of men with HLH who exhibit evidence of androgen deficiency is currently unknown. These uncertainties pose important questions regarding the clinical significance of abnormally increased $\mathrm{LH}$ in ageing men. ${ }^{3}$ The European Male Ageing Study (EMAS) $)^{4,5}$ provides an opportunity to help rectify these knowledge gaps through longitudinal observations of unselected men from the general population.

This article is protected by copyright. All rights reserved. 
In this study, we aimed to: 1) identify factors predisposing normal LH men to develop high $\mathrm{LH}$ and to identify factors, which predict recovery from high $\mathrm{LH} ; 2$ ) determine the clinical features associated with high $\mathrm{LH}$; and 3) assess whether men with high $\mathrm{LH}$ are at increased risk of developing PHG.

\section{Materials and Methods}

\section{Participants and study design}

The study design and recruitment for EMAS have been described previously. ${ }^{4,5}$ Briefly, an age-stratified sample of 3,369 men aged 40-79 (mean $\pm S D: 60 \pm 11)$ years was recruited from population registers in eight European centres. Participants completed a postal questionnaire and attended a clinic for further assessments. These men were invited to participate in the follow-up assessment a median of 4.3 years later (range: $3.0-5.7$ years). During this period, 168 men died and 407 men were lost to follow-up. Ethical approval for the study was obtained in accordance with local requirements in each centre. All participants provided written, informed consent. They completed questionnaires both at baseline and at follow-up ${ }^{4,5}$ about smoking, alcohol consumption, and currently treated medical conditions. ${ }^{3}$ Anthropometric measurements, Reuben's physical performance test (PPT), and psychomotor processing speed estimation (digit symbol substitution test [DSST]) were performed according to standardized methods. ${ }^{4,5}$ Physical, sexual and psychological function was assessed using responses to the Medical Outcome Study (MOS) 36-item Short-Form health survey (SF36), the EMAS Sexual Function Questionnaire and the Beck's Depression Inventory.

\section{Hormone measurements}

A single fasting morning (before 1000) blood sample was obtained at baseline and at followup. T was measured by liquid chromatography-tandem mass spectrometry (LC-MS/MS), ${ }^{6}$ with paired baseline and follow-up samples analysed simultaneously. LH, FSH and SHBG were measured by the E170 platform electrochemiluminescence immunoassay (Roche 
Diagnostics). The Vermeulen formula was used to calculate free (f) $T^{7}$ using participantspecific testosterone, SBHG and albumin values. Intra- and inter-assay coefficients of variation (CV) were: T 4.0 and 5.6\%; LH 1.9 and 2.7\%; FSH 0.9 and 1.9\%; and SHBG 1.9 and $3.2 \%$, respectively. The detection limits for the sex hormones were: $\mathrm{T}(0.17 \mathrm{nmol} / \mathrm{L} ; 0.05$ $\mathrm{ng} / \mathrm{mL}), \mathrm{LH}(0.10 \mathrm{U} / \mathrm{L}), \mathrm{FSH}(0.10 \mathrm{U} / \mathrm{L})$ and SHBG $(0.35 \mathrm{nmol} / \mathrm{L})$. Insulin was assayed using chemiluminescence (CVs: $3.9 \%$ and $5 \%)$.

\section{Biochemistry/haematology}

Standardized measurements were undertaken in laboratories in each centre. Insulin resistance was calculated using the homeostasis model assessment of insulin resistance $(\mathrm{HOMA}-\mathrm{IR}=$ fasting insulin $[\mathrm{U} / \mathrm{mL}] \times$ fasting glucose $[\mathrm{mmol} / \mathrm{L}] / 22.5) .{ }^{8}$

\section{Categorisation of participants by $\mathrm{LH}$ criteria}

Following the criteria described previously, ${ }^{2}$ participants were categorised according to $\mathrm{LH}$ and T levels: normal LH (NLH, LH $\leq 9.4 \mathrm{U} / \mathrm{L}$ and $\mathrm{T} \geq 10.5 \mathrm{nmol} / \mathrm{L})$; high $\mathrm{LH}(\mathrm{HLH}, \mathrm{LH}>9.4 \mathrm{U} / \mathrm{L}$ and $\mathrm{T} \geq 10.5 \mathrm{nmol} / \mathrm{L}$ ). A LH cut-off of $9.4 \mathrm{U} / \mathrm{L}$ was chosen because this was the 97.5 centile value for men aged 40 to 44 years in the EMAS population. ${ }^{9}$ Participants were further categorised by their change in LH status into one of four groups: incident HLH (iHLH) in which men had a normal LH at baseline and an high LH at follow-up; persistent HLH (pHLH) in which men had HLH at both baseline and follow-up; reverted HLH (rHLH) in which men had $\mathrm{HLH}$ at baseline and NLH at follow-up; and pNLH in which men had NLH at both baseline and follow-up.

\section{Statistical analysis}

Baseline and follow-up differences between pNLH, iHLH, pHLH and rHLH men in hormone levels, anthropometrics, biochemistry, sexual, physical and psychological function, and health and lifestyle measures were compared between groups using initially the independent-samples t-test or analyses of variance (ANOVA) for continuous variables and $x^{2}$ 
tests for categorical variables. Post-hoc analyses were performed using Tukey-Kramer tests to allow for multiple pairwise comparisons. Longitudinal within-group differences in parameters were compared using the paired t-test for continuous variables and the McNemar test for categorical variables.

Multiple regression models, adjusted for centre as a random effect, were used to account for the hierarchical study design (individuals nested within centres). The relationships between LH status and putative predictors were assessed using multilevel binary logistic regression models, where gonadal status was the outcome, with the pNLH or pHLH group being the referent for the analyses of the potential predictors for iHLH or rHLH respectively. Nine factors were included as fixed effects: age (40-49 years, 50-59 years, 60-69 years or $\geq 70$ years), diabetes, BMI (<25 kg/m², $25-29.9 \mathrm{~kg} / \mathrm{m}^{2}$ or $\geq 30 \mathrm{~kg} / \mathrm{m}^{2}$ ), smoking status (current, ex or never), alcohol intake ( $\geq 5$ days per week or $<5$ days per week), chronic pain, pre-degree education (education obtained to below a university degree level), partner status (living with a partner or not) and physical activity (PASE $\leq 78$ or $>78)$. The factors chosen were not collinear - the variance inflation factors were less than 3.33.

The relationships between gonadal status and clinical features of high $\mathrm{LH}$ were investigated using binary logistic regression models when associations between $\mathrm{iH} L \mathrm{H}, \mathrm{pH} L \mathrm{H}$ or $\mathrm{rHLH}$ status with sexual, physical and psychological symptoms or medical conditions were assessed, with adjustments for age, comorbidities, BMI, centre, smoking, chronic pain, education and physical activity. Linear regression analysis was used when associations between $\mathrm{iHLH}, \mathrm{pHLH}$ or rHLH status with functional ratings were assessed, with adjustments for age, comorbidities, BMI, centre, smoking, chronic pain, education and physical activity. Results from linear regression models are presented as $\beta$-coefficients (for standardized variables) with 95\% confidence intervals $(\mathrm{Cl})$ and results from logistic regression models are presented as odds ratios (OR) with $95 \% \mathrm{Cl}$. All statistical analyses were conducted using STATA SE version 13 (StataCorp, College Station, TX).

This article is protected by copyright. All rights reserved. 


\section{Results}

Natural history of High $\mathrm{LH}$

Of the 3,369 men recruited into EMAS, 1,942 men made up the analytical sample after exclusion of those with known pituitary, testicular or adrenal disease $(n=93)$, men using a medication known to affect the HPT-axis ( $n=217)$, men who had surgical or medical castration $(n=2)$, men who failed to attend for follow-up assessment $(n=575)$, men with missing $T(n=77)$ or $\mathrm{LH}(\mathrm{n}=45)$ data and men with a testosterone level less than $10.5 \mathrm{nmol} / \mathrm{L}$ at baseline or follow-up ( $n=418$, Figure 1). Men with testosterone levels less than 10.5 $\mathrm{nmol} / \mathrm{L}$ in EMAS have been described separately. ${ }^{10,11}$ Men who died or were lost to follow-up were older, in poorer health, had worse physical and cognitive function and were more likely to smoke (Supplementary Table 1). This attritional group had also lower fT and higher SHBG and LH levels than the analytical sample.

Of 305 (9.6\%) men who had HLH at baseline, 36 died, 50 were lost to follow-up, 19 developed medical exclusions (e.g. started taking HPT-axis affecting drugs) and 7 had no follow-up hormone data. In the remaining 193 men with $\mathrm{HLH}$ at baseline with available follow-up data, 128 (66.3\%) continued to have HLH at follow-up, $46(23.8 \%)$ reverted to NLH, 15 (7.8\%) developed PHG and 4 (2.1\%) developed SHG. The annual incidence of PHG among men with HLH at baseline was $1.8(1.1-3.0) \% /$ year.

The analytical sample comprised 1,667 (85.8\%) men with pNLH, $101(5.2 \%)$ with iHLH, 128 (6.6\%) with pHLH and 46 (2.4\%) rHLH men. The incidence (95\% confidence interval) of HLH over the follow-up period was $5.7(4.7-6.8) \%$ and the annual incidence rate was $1.3(1.1$ 1.6)\%/year assuming linearity of $\mathrm{HLH}$ development. The recovery rate from $\mathrm{HLH}$ to NLH was $26.4(20.5-33.5) \%$ and annual recovery rate was $6.8(5.1-8.9) \% / y e a r$. The prevalence of HLH at follow-up was $9.5 \%(n=229)$.

This article is protected by copyright. All rights reserved. 


\section{Characteristics of men who developed high $\mathrm{LH}$}

Age, depression (BDI), fasting glucose and PSA were higher, and cognitive function (DSST) and physical activity level (PASE) were lower in iHLH men, at baseline, compared with pNLH men (Table 1). Subjective physical function (SF-36 ratings) and objective physical function (PPT score) were lower in iHLH men at baseline. At follow-up, these earlier differences between the groups persisted, while iHLH men also had lower haemoglobin. The prevalence of poor health and chronic illnesses was higher in the iHLH group than in the pNLH group at both baseline and follow-up (Table 1).

Total T levels were similar in iHLH men and pNLH men at baseline and at follow-up (Table 1). Men with iHLH, compared to pNLH men, had lower fT at baseline $(298 \pm 94$ vs. $327 \pm 77$ $\mathrm{pmol} / \mathrm{L}, \mathrm{p}<0.001)$ and at follow-up (282 $\pm 84 \mathrm{vs.} 313 \pm 76 \mathrm{pmol} / \mathrm{L}, \mathrm{p}<0.001)$ which may have been due to age-related higher SHBG levels at both time-points. As expected by definition, LH levels were higher in iHLH men than in pNLH men (Figure 2).

\section{Characteristics of men who recovered from high $\mathrm{LH}$}

Men with rHLH, compared to those with $\mathrm{pHLH}$, were younger, had a lower co-morbidity burden and BMI, and had higher sexual function, cognitive processing speed and physical function at baseline. These baseline differences persisted at follow-up except for BMI (Supplementary table 2).

Men with rHLH had similar T levels at baseline and at follow-up to men with pHLH (Supplementary table 2). Men with rHLH, however, had higher fT levels, compared to men with $\mathrm{pHLH}$, at baseline ( $333 \pm 90$ vs $269 \pm 74 \mathrm{pmol} / \mathrm{L}, \mathrm{p}<0.001)$ and at follow-up (312 \pm 87 vs $246 \pm 74 \mathrm{pmol} / \mathrm{L}, \mathrm{p}<.001)$. LH levels were lower at baseline and at follow-up in rHLH men compared to $\mathrm{pHLH}$ men (Figure 2).

This article is protected by copyright. All rights reserved. 
Predictors of high LH development and recovery

In men with NLH at baseline, the development of HLH was predicted independently by high age (>70 years, OR 4.12 [2.07-8.20], $p<0.001$ ), diabetes (OR 2.86 [1.42-5.77], $p=0.003$ ), chronic pain (OR 2.53 [1.34-4.77], $\mathrm{p}=0.004$ ), education to a below university degree level (OR 1.79 [1.01-3.20], p=0.047) and low physical activity (PASE $\leq 78$, OR 2.37 [1.24-4.50], $\mathrm{p}=0.009$, Figure 3).

In men with $\mathrm{HLH}$ at baseline, recovery from HLH was predicted independently by younger age (40-49 years, OR 8.14 [1.35-49.13], $\mathrm{p}=0.022$ and 50-59 years, OR 3.38 [1.12-10.19], $\mathrm{p}=0.030$ ) and by non-smoker status (OR 5.39 [1.48-19.65], $\mathrm{p}=0.011$, Figure 3).

\section{Symptoms and high $\mathrm{LH}$}

At baseline, NLH men who developed HLH did not report a higher frequency of symptoms compared to $\mathrm{pNLH}$ men, apart from sadness. Furthermore, they were less likely to report an inability to bend (Figure 4). At follow-up, men with incident HLH were more likely to experience only a worsening of erectile function, but none of the other 8 symptoms.

Men with pHLH and pNLH men did not differ in symptom frequency at baseline - pHLH men were more likely to develop inability to bend, but none of the other symptoms.

The prevalence and incidence of symptoms were similar between $\mathrm{rHLH}$ and $\mathrm{pHLH}$ men at baseline or follow-up (Figure 4).

\section{Co-morbidities, Functional Ratings and High $\mathrm{LH}$}

At baseline, men with iHLH were more likely to have diabetes, insulin resistance, lower haemoglobin and lower mood (SF-36 mental) than pNLH men (Table 2). At follow-up, men with iHLH experienced a greater rise in time taken to walk 50 feet, a greater fall in haemoglobin and were more likely to develop poor health, cardiovascular disease and cancer than men with pNLH. 
At baseline, men with pHLH were more likely to have diabetes and cancer, lower cognitive processing speed (DSST), higher insulin resistance and lower haemoglobin levels than men with $\mathrm{pNLH}$. During follow-up, men with $\mathrm{pHLH}$, compared to men with $\mathrm{pNLH}$, were more likely to develop co-morbidity, including CVD, while physical function (PPT-rating) and cognitive processing speed worsened more (Table 2).

\section{Progression from High LH to Primary Hypogonadism (PHG)}

Men with HLH at baseline were more likely to develop PHG in both unadjusted analysis (OR 21.77 [8.76-54.12], $\mathrm{p}<0.001$ ) and in fully adjusted analysis (OR 15.10 [5.54-41.20], $\mathrm{p}<0.001$ ) than were NLH men. The annual rate of progression from HLH to PHG was $1.8 \% /$ year [1.13.0] [total progression rate was $7.8 \%(4.8-12.4])$.

Men who transitioned from HLH to PHG, compared to pHLH men, had lower T $(13.5 \pm 2.5$ vs. $19.1 \pm 5.5 \mathrm{nmol} / \mathrm{L}, \mathrm{p}<0.001)$ and fT levels (189 $\pm 57 \mathrm{vs} .269 \pm 74 \mathrm{pmol} / \mathrm{L}, \mathrm{p}<0.001)$ at baseline, while LH (20.4 \pm 15.5 vs. $14.4 \pm 4.8 \mathrm{U} / \mathrm{L}, \mathrm{p}=0.306)$ and SHBG levels $(68.4 \pm 50.1$ vs. $61.4 \pm 21.5$ $\mathrm{nmol} / \mathrm{L}, \mathrm{p}=0.388$ ) were similar. The transition from $\mathrm{HLH}$ to $\mathrm{PHG}$ was underlined by noteworthy declines in both $\mathrm{T}(-4.8 \pm 3.5 \mathrm{nmol} / \mathrm{L}$ and $-34.2 \pm 21.2 \%)$ and $\mathrm{fT}(-58 \pm 40 \mathrm{pmol} / \mathrm{L}$ and $-33.3 \pm 22.1 \%$ ), even though $\mathrm{T}$ and $\mathrm{fT}$ levels were already lower at both baseline and followup compared to other groups.

\section{Discussion}

In this prospective and longitudinal analysis of 3,369 community-dwelling men, we have described, for the first time, the natural history and clinical phenotype of men who develop elevated LH (and normal T), have identified risk factors predisposing to the development of HLH and documented the likelihood of progression to PHG and recovery from HLH. Men who go onto develop HLH, compared to men who do not, experience a greater fall in haemoglobin and walking speed with increased risks of developing CVD and cancer. These findings, together with the persistently normal mean $T$ of $\geq 18 \mathrm{nmol} / \mathrm{L}$ and a lack of decreased libido and morning erections, suggest that the clinical correlates of $\mathrm{iHLH}$ are not typical of hypogonadism, but rather represent those associated with poor or deteriorating health. This 
is reinforced further by our findings showing that $\mathrm{pHLH}$ men have lower levels of haemoglobin and cognitive function (DSST) at baseline, greater worsening of DSST and physical functioning over time, and increased comorbidity at baseline (diabetes and cancer) and follow-up (CVD).

We have hypothesised previously that compensated hypogonadism (here referred to as $\mathrm{HLH}$ ) may be a transitional state, which presages the development of overt $\mathrm{PHG}{ }^{2}$ We show now that the development of HLH is predicted independently by age $>70$ years, diabetes, chronic pain, pre-degree education and low physical activity. The longitudinal association between high age and $\mathrm{iHLH}$ reinforces our previous cross-sectional results. ${ }^{2}$ This association, together with the novel identification of diabetes, pain and physical activity as factors that predispose to the development of $\mathrm{HLH}$, suggest that $\mathrm{HLH}$ can be regarded as a feature of functional ageing. The possible link between socioeconomic factors (education to a less than university degree level) and the development of HLH presents a fresh perspective on the predisposition to adverse outcomes of endocrine ageing. It is recognised that people with better educational attainment are healthier and live longer ${ }^{12}-$ it may be that Leydig cell functional reserve plays a mediating role in this relationship. Interestingly, obesity is not a predictor of $\mathrm{HLH}$, yet the occurrence of $\mathrm{HLH}$ appears to be predicted by diabetes. In this respect, $\mathrm{HLH}$ is more closely linked to $\mathrm{PHG}^{11}$ than to $\mathrm{SHG}$ which is related to obesity and not to age or chronic illness. ${ }^{10}$ This highlights the different underlying pathophysiological mechanisms contributing to the decline in $\mathrm{T}$ in older men as well as their distinct clinical implications.

It follows that a vicious circle may exist for men with $\mathrm{HLH}$ - factors associated with accelerated functional ageing (diabetes, chronic pain, physical inactivity) predispose to HLH development and $\mathrm{HLH}$, in turn, predisposes to further functional decline (decrease in haemoglobin, physical function and cognitive function as well as development of CVD). With a baseline prevalence of HLH in EMAS of $9.4 \%,{ }^{2}$ an incidence rate of $1.3 \% / y e a r$ and recovery rate of $6.8 \% / y e a r, \mathrm{HLH}$ appears to be a relatively common but reversible condition in the general population. Recovery from HLH was associated with younger age and being 
a non-smoker. It is plausible, that, as compared to pHLH men, the younger rHLH men might have a higher reserve of testicular steroidogenic function or Leydig cell population, which allowed them to compensate for potential insults to Leydig cells due to disease. Less likely is the possibility that younger and healthier men had greater LH pulsatility (vide infra) increasing their chance of being classified as $\mathrm{HLH}$ at baseline due to blood taking during an LH pulse. The observation that non-smoking is a predictor for the recovery from HLH is in agreement with our baseline cross-sectional findings showing that smoking status is related to $\mathrm{HLH}^{2}{ }^{2}$ The higher SHBG levels observed in smokers might explain this finding, ${ }^{13}$ although the exact mechanism, remains unclear. Except for minor changes in BMI, none of the androgen-sensitive endpoints or medical conditions assessed within our study were associated or changed with $\mathrm{rHLH}$. This supports the view that HLH is not a hypogonadal condition although a significant proportion of HLH men will go on to develop PHG within the ensuing 5 years.

The HPT axis is regulated tightly in older as in young men ${ }^{14}$ and elevated LH is highly responsive to age-related deficits in Leydig cell mass ${ }^{15}$ and function. ${ }^{16}$ Impaired testicular response to LH can be caused by exposure to cytokines, ${ }^{17,18}$ arising from chronic low grade inflammation, ${ }^{19}$ which is common in ageing. ${ }^{20}$ Testicular failure with elevated gonadotropins is also associated with chronic diseases of ageing including cancer, ${ }^{21}$ diabetes, ${ }^{22}$ renal and liver failure and COPD. ${ }^{23}$ In addition, elevated $\mathrm{LH}$, independent of testicular failure, has been associated with increased all-cause and cancer-specific mortality. ${ }^{24}$ Elevated LH can be therefore considered a biomarker of poor health and subclinical chronic diseases.

Accordingly, $\mathrm{iHLH}$ is predicted by the presence of diabetes, and iHLH men are at risk of developing CVD and cancer.

\section{Strengths and limitations}

This prospective study provided an opportunity to investigate the temporal relationships between the earliest ageing-related changes in HPT-axis function and their clinical correlates. The strengths of the study include the longitudinal follow-up of a large number of

This article is protected by copyright. All rights reserved. 
unselected participants from the general population and the breadth of the phenotypic data collected by standardised validated methods between the phases of the study. T was measured by LC-MS/MS with paired baseline and follow-up samples analysed simultaneously. Limitations in EMAS have been described previously. ${ }^{4,5}$ The follow-up period of 4.3 (range: $3.0-5.7$ ) years may be a relatively short time in which to capture more protracted changes in signs and symptoms of hypogonadism. A relatively small number of men developed $\mathrm{HLH}$ - this is unavoidable given the relatively low incidence of the condition which has not been previously described. However, the ability to identify significant and consistent associations (albeit with wide confidence intervals) despite the relatively small numbers of cases supports the validity of our findings and conclusions. At both study phases, a single LH and T measurement only was available to categorise gonadal status. This may have introduced errors in classification although the consistency of higher LH between baseline and follow-up and the parallel changes in FSH add confidence to our

results. Multiple blood sample collection is impractical in large epidemiological surveys ${ }^{25,26}$ such as ours. Several studies have confirmed that T levels within the same individual do not fluctuate significantly when measured serially over several months. ${ }^{27-30}$ Similarly, the diurnal variation in $\mathrm{LH}$ levels is markedly less prominent, if not absent, in older men. ${ }^{31}$ In our analytical sample, the co-efficients of correlation between baseline and follow-up T and LH levels were $0.72(p<0.001)$ and $0.80(p<0.001)$ respectively. It is unlikely, therefore, that single hormone determination in the present study would have introduced substantial misclassification of gonadal status. The fact that the vast majority of EMAS participants had a normal $\mathrm{LH}$ at baseline and at follow-up and the parallel changes in FSH attest to this.

\section{Conclusions and clinical implications}

Age greater than 70 years, diabetes, chronic pain, pre-degree education and low physical activity predispose men to the development of high $\mathrm{LH}$, which may be reversible in younger men. High LH, (with normal T), can be regarded as a sensitive biomarker of poor health and a risk factor for developing PHG. Incident HLH is not associated with unequivocal evidence 
of androgen deficiency. Even if HLH persists for several years, the emergent physical and cognitive impairments are not typical features of hypogonadism, but rather reflect deteriorating health during ageing.

In clinical practice, men with elevated LH and normal T should be followed up for their general as well as endocrine reproductive health, but there is no indication for $\mathrm{T}$ replacement therapy unless $T$ falls into the hypogonadal range and more features of androgen deficiency appear (i.e. progression to PHG).

\section{Declaration of Interest}

FCWW has acted as a consultant for Bayer-Schering, Eli Lilly and Besins Healthcare and also participated in advisory board meetings and lectured on their behalf. FCWW has received lecture fees from Bayer-Schering and Besins Healthcare. FCWW has received grant support (2010-2014) from Bayer Schering AG and Besins Healthcare. ITH is a consultant and/or has received grants from Ferring Pharmaceuticals and Novartis. All other authors have nothing to disclose.

\section{Funding}

The European Male Ageing Study is funded by the Commission of the European Communities Fifth Framework Programme "Quality of Life and Management of Living Resources" Grant QLK6-CT-2001-00258.

This article is protected by copyright. All rights reserved. 


\section{References}

1 Lamberts, S.W., van den Beld, A.W. \& van der Lely, A.J. (1997) The endocrinology of aging. Science; 278: 419-424.

2 Tajar, A., Forti, G., O'Neill, T.W., et al. (2010) Characteristics of secondary, primary, and compensated hypogonadism in aging men: evidence from the European Male Ageing Study. J Clin Endocrinol Metab; 95: 1810-1818.

3 Wu, F.C., Tajar, A., Pye, S.R., et al. (2008) Hypothalamic-pituitary-testicular axis disruptions in older men are differentially linked to age and modifiable risk factors: the European Male Aging Study. J Clin Endocrinol Metab; 93: 2737-2745.

4 Lee, D.M., O'Neill, T.W., Pye, S.R., et al. (2009) The European Male Ageing Study (EMAS): design, methods and recruitment. Int J Androl; 32: 11-24.

5 Lee, D.M., Pye, S.R., Tajar, A., et al. (2013) Cohort profile: the European Male Ageing Study. Int J Epidemiol; 42: 391-401.

6 Gallagher, L.M., Owen, L.J. \& Keevil, B.G. (2007) Simultaneous determination of androstenedione and testosterone in human serum by liquid chromatography-tandem mass spectrometry. Ann Clin Biochem; 44: 48-56.

7 Vermeulen, A., Stoica, T. \& Verdonck, L. (1971) The apparent free testosterone concentration, an index of androgenicity. J Clin Endocrinol Metab; 33: 759-767.

8 Matthews, D.R., Hosker, J.P., Rudenski, A.S., et al. (1985) Homeostasis model assessment: insulin resistance and beta-cell function from fasting plasma glucose and insulin concentrations in man. Diabetologia; 28: 412-419.

9 Tajar, A., O'Connell, M.D., Mitnitski, A.B., et al. (2011) Frailty in relation to variations in hormone levels of the hypothalamic-pituitary-testicular axis in older men: results from the European male aging study. J Am Geriatr Soc; 59: 814-821.

10 Rastrelli, G., Carter, E.L., Ahern, T., et al. (2015) Development of and Recovery from Secondary Hypogonadism in Aging Men: Prospective Results from the EMAS. J Clin Endocrinol Metab; 100: 3172-3182.

This article is protected by copyright. All rights reserved. 
11 Ahern, T., Swiecicka, A., Eendebak, R.J., et al. (2016) Natural history, risk factors and clinical features of primary hypogonadism in ageing men: Longitudinal Data from the European Male Ageing Study. Clin Endocrinol (Oxf); 85: 891-901.

12 Baker, D.P., Leon, J., Smith Greenaway, E.G., Collins, J. \& Movit, M. (2011) The education effect on population health: a reassessment. Popul Dev Rev; 37: 307-332.

13 Field, A.E., Colditz, G.A., Willett, W.C., Longcope, C. \& McKinlay, J.B. (1994) The relation of smoking, age, relative weight, and dietary intake to serum adrenal steroids, sex hormones, and sex hormone-binding globulin in middle-aged men. J Clin Endocrinol Metab; 79: $1310-1316$

14 Keenan, D.M., Takahashi, P.Y., Liu, P.Y., et al. (2006) An ensemble model of the male gonadal axis: illustrative application in aging men. Endocrinology; 147: 2817-2828.

15 Neaves, W.B., Johnson, L., Porter, J.C., Parker, C.R., Jr. \& Petty, C.S. (1984) Leydig cell numbers, daily sperm production, and serum gonadotropin levels in aging men. $J$ Clin Endocrinol Metab; 59: 756-763.

16 Veldhuis, J.D., Liu, P.Y., Keenan, D.M. \& Takahashi, P.Y. (2012) Older men exhibit reduced efficacy of and heightened potency downregulation by intravenous pulses of recombinant human LH: a study in 92 healthy men. Am J Physiol Endocrinol Metab; 302: E117-122.

17 van der Poll, T., Romijn, J.A., Endert, E. \& Sauerwein, H.P. (1993) Effects of tumor necrosis factor on the hypothalamic-pituitary-testicular axis in healthy men. Metabolism; 42: 303-307.

18 Hong, C.Y., Park, J.H., Ahn, R.S., et al. (2004) Molecular mechanism of suppression of testicular steroidogenesis by proinflammatory cytokine tumor necrosis factor alpha. Mol Cell Biol; 24: 2593-2604.

19 Haring, R., Baumeister, S.E., Volzke, H., et al. (2012) Prospective inverse associations of sex hormone concentrations in men with biomarkers of inflammation and oxidative stress. J Androl; 33: 944-950.

This article is protected by copyright. All rights reserved. 
20 Calcada, D., Vianello, D., Giampieri, E., et al. (2014) The role of low-grade inflammation and metabolic flexibility in aging and nutritional modulation thereof: a systems biology approach. Mech Ageing Dev; 136-137: 138-147.

21 Garcia, J.M., Li, H., Mann, D., et al. (2006) Hypogonadism in male patients with cancer. Cancer; 106: 2583-2591.

22 Schoeller, E.L., Schon, S. \& Moley, K.H. (2012) The effects of type 1 diabetes on the hypothalamic, pituitary and testes axis. Cell Tissue Res; 349: 839-847.

23 Kaparianos, A., Argyropoulou, E., Efremidis, G. \& Spiropoulos, K. (2011) Sex hormone alterations and systemic inflammation in a group of male COPD smokers and their correlation with the +138 ins $\mathrm{A} / \mathrm{del} \mathrm{A}$ endothelin-1 gene polymorphism. A case-control study . Eur Rev Med Pharmacol Sci; 15: 1149-1157.

24 Holmboe, S.A., Vradi, E., Jensen, T.K., et al. (2015) The Association of Reproductive Hormone Levels and All-Cause, Cancer, and Cardiovascular Disease Mortality in Men. $J$ Clin Endocrinol Metab; 100: 4472-4480.

25 Harman, S.M., Metter, E.J., Tobin, J.D., Pearson, J. \& Blackman, M.R. (2001) Longitudinal effects of aging on serum total and free testosterone levels in healthy men. Baltimore Longitudinal Study of Aging. J Clin Endocrinol Metab; 86: 724-731.

26 Travison, T.G., Shackelton, R., Araujo, A.B., et al. (2008) The natural history of symptomatic androgen deficiency in men: onset, progression, and spontaneous remission. $J$ Am Geriatr Soc; 56: 831-839.

27 Keevil, B.G., MacDonald, P., Macdowall, W., et al. (2014) Salivary testosterone measurement by liquid chromatography tandem mass spectrometry in adult males and females. Ann Clin Biochem; 51: 368-378.

28 Srinivas-Shankar, U., Roberts, S.A., Connolly, M.J., et al. (2010) Effects of testosterone on muscle strength, physical function, body composition, and quality of life in intermediate-frail and frail elderly men: a randomized, double-blind, placebo-controlled study. J Clin Endocrinol Metab; 95: 639-650.

This article is protected by copyright. All rights reserved. 
29 Vermeulen, A. \& Verdonck, G. (1992) Representativeness of a single point plasma testosterone level for the long term hormonal milieu in men. J Clin Endocrinol Metab; 74: 939-942.

30 Finkelstein, J.S., Lee, H., Burnett-Bowie, S.A., et al. (2013) Gonadal steroids and body composition, strength, and sexual function in men. N Engl J Med; 369: 1011-1022.

31 Brambilla, D.J., Matsumoto, A.M., Araujo, A.B. \& McKinlay, J.B. (2009) The effect of diurnal variation on clinical measurement of serum testosterone and other sex hormone levels in men. J Clin Endocrinol Metab; 94: 907-913.

\section{Figure Legends}

Fig. 1. Flowchart of Participants

pNLH, persistent Normal LH; iHLH, incident High LH; pHLH, persistent High LH; and rHLH, recovery from High LH.

Fig. 2. Sex hormone levels and LH status at baseline and follow-up for men with persistent Normal LH (pNLH), incident HLH (iHLH), persistent HLH (pHLH), and recovery from HLH $(\mathrm{rHLH})$

Baseline and follow-up hormone concentrations are expressed as means (upper limits of bars) and as standard errors of the means (upper limits of the error bars). Data in the groups were compared, and p-values were generated, using analyses of variance (ANOVA) and Tukey-Kramer post-hoc analyses to permit correction for multiple pairwise comparisons.

Solid black bars at follow-up with the letter 'a' indicate that follow-up hormone levels in this group differed significantly from baseline hormone levels in the same group when analysed using the paired t-test.

Lines and brackets with stars above bars indicate statistically significant differences between the two groups $(p<0.05)$. The horizontal dotted lines represent values above or below which 
are considered abnormal $(10.5 \mathrm{nmol} / \mathrm{L}$ for total testosterone, $220 \mathrm{pmol} / \mathrm{L}$ for calculated free testosterone, and $9.4 \mathrm{U} / \mathrm{L}$ for luteinising hormone).

Fig. 3. Potential Risk Factors for development of, and recovery from, High LH

Data are expressed as odds ratio (symbol) $\pm 95 \%$ confidence interval (error bars). In the left panels, odds ratios and $p$-values were determined using single independent variables and binary logistic regression analyses (unadjusted/univariate). In the right panels, odds ratios and $p$-values were determined using multiple binary logistic regression analysis including all the potential risk factors listed in the same model.

${ }^{*}, \mathrm{p}<0.05 ;{ }^{* *}, \mathrm{p}<0.01 ;{ }^{* * *}, \mathrm{p}<0.001$

Fig. 4. Relationships between Symptoms and High LH.

Data are expressed as odds ratios ( $\mathbf{\Delta}) \pm 95 \%$ confidence intervals (error bars). Odds ratios and $\mathrm{p}$-values were determined using regression analyses. Data from the incident high $\mathrm{LH}$ (iHLH) and persistent high $\mathrm{LH}(\mathrm{pHLH})$ groups were compared to those from the referent group of persistent normal LH (pNLH). Recovery from high LH ( $\mathrm{rHLH})$ data were compared to those of pHLH men. The statistical analysis was performed with adjustment for age, comorbidity, body mass index, centre, chronic pain, education, smoking, and physical activity. The left panels show the odds ratios for the prevalence of symptoms at baseline. The right panels show the odds ratios for the development/worsening of symptoms.

${ }^{*}, p<0.05 ;{ }^{* *}, p<0.01$.

This article is protected by copyright. All rights reserved. 
Table 1. Baseline and Follow-Up Characteristics of Men with Persistently Normal LH and those with Incident High LH

\section{Parameter}

$N$

Age, years

Pre-degree Education ${ }^{c}, \mathrm{n}(\%)$

Living with partner, $\mathrm{n}(\%)$

Smoking, $\mathrm{n}(\%)$

Frequent Alcohol, $\mathrm{n}(\%)$

Chronic widespread pain, $\mathrm{n}(\%)$

Poor health, $\mathrm{n}(\%)$

$\geq 1$ illness, $\mathrm{n}(\%)$

$\geq 2$ illnesses, $\mathrm{n}(\%)$

Diabetes, $\mathrm{n}(\%)$

CVD, n (\%)

Prostate disease, $n(\%)$

Overall Sexual Function

SF-36 physical

Beck's Depression Inventory

SF-36 mental

DSST

PASE score

50-ft walk, sec

PPT rating
BMI, $\mathrm{kg} / \mathrm{m}^{2}$

$\mathrm{FPG}, \mathrm{mmol} / \mathrm{L}$

HOMA-IR

PSA, $\mathrm{ng} / \mathrm{ml}$

$\mathrm{Hb}, \mathrm{g} / \mathrm{L}$

Total T, nmol/L

Free T, pmol/L

SHBG, nmol/L

$\mathrm{LH}, \mathrm{U} / \mathrm{L}$

\begin{tabular}{|c|c|}
\hline \multicolumn{2}{|c|}{ Baseline } \\
\hline $\begin{array}{l}\text { pNLH } \\
1,667\end{array}$ & $\begin{array}{c}\text { iHLH } \\
101\end{array}$ \\
\hline$\frac{, 00}{57.2 \pm 10.1}$ & $63.9 \pm 10.9$ \\
\hline --- & --- \\
\hline --- & --- \\
\hline $333(20.2)$ & $23(22.8)$ \\
\hline $415(25.0)$ & $22(21.8)$ \\
\hline $122(7.6)$ & 14 (14.4) \\
\hline 308 (18.6) & 31 (31.0) \\
\hline $593(35.6)$ & $50(49.5)$ \\
\hline 216 (16.7) & $22(30.1)$ \\
\hline 73 (4.4) & $15(15.0)$ \\
\hline 466 (28.4) & $37(37.0)$ \\
\hline $59(3.5)$ & $4(4.0)$ \\
\hline 135 (8.2) & $5(5.0)$ \\
\hline $22.5 \pm 6.4$ & $20.2 \pm 7.2$ \\
\hline $51.5 \pm 7.3$ & $49.7 \pm 8.4$ \\
\hline $6.1 \pm 5.9$ & $8.0 \pm 6.8$ \\
\hline $52.1 \pm 8.7$ & $50.3 \pm 8.4$ \\
\hline $29.5 \pm 8.1$ & $25.3 \pm 8.6$ \\
\hline $211.4 \pm 86.4$ & $183.5 \pm 95.1$ \\
\hline $13.0 \pm 2.8$ & $13.5 \pm 2.8$ \\
\hline $24.4 \pm 2.4$ & $23.8 \pm 2.7$ \\
\hline $27.2 \pm 3.8$ & $27.2 \pm 4.1$ \\
\hline $5.4 \pm 0.9$ & $5.9 \pm 1.5$ \\
\hline $2.7 \pm 2.6$ & $3.6 \pm 7.5$ \\
\hline $1.5 \pm 2.1$ & $2.2 \pm 3.6$ \\
\hline $150.8 \pm 10.4$ & $148.5 \pm 11.2$ \\
\hline $18.4 \pm 5.4$ & $18.0 \pm 5.1$ \\
\hline $326.7 \pm 77.4$ & $298.4 \pm 93.7$ \\
\hline $42.9 \pm 17.3$ & $48.3 \pm 17.0$ \\
\hline $5.0 \pm 1.7$ & $7.4 \pm 1.4$ \\
\hline
\end{tabular}

\begin{tabular}{l}
$P^{a}$ \\
\hline$<.001$ \\
-- \\
-- \\
0.521 \\
0.758 \\
0.145 \\
$<.001$ \\
$<.001$ \\
$<.001$ \\
$<.001$ \\
0.001 \\
$<.001$ \\
0.003 \\
0.002 \\
0.031 \\
0.003 \\
0.016 \\
$<.001$ \\
0.005 \\
0.040 \\
0.035 \\
0.935 \\
0.006 \\
0.647 \\
0.003 \\
0.053 \\
0.611 \\
$<.001$ \\
$<.001$ \\
$<.001$ \\
$<.001$
\end{tabular}

$\mathrm{pNLH}$
1,667

$61.6 \pm 10.1^{* * \star}$

$1132(69.2)$

$1325(85.0)$

$285(17.7)^{* * \star}$
$519(35.9)^{* * *}$

$519(35.9)$

$353(21.9)^{\star \star \star}$

$379(50.2)^{\star \star \star}$

$438(34.5)^{\star * *}$

$91(5.6)^{* * \star}$

$588(37.6)^{\star \star \star \star}$

$114(7.2)^{\star \star \star}$

$156(9.7)^{\star}$

$21.7 \pm 6.7^{* *}$

$6.0 \pm 6.4$

$52.0 \pm 9.2$

$52.0 \pm 9.2$
$28.7 \pm 8.6^{* * \star}$

$28.7 \pm 8.6^{\star \star \star}$
$186.9 \pm 92.7^{\star * *}$

$13.6 \pm 2.8^{* * *}$

$24.0 \pm 2.4^{* * *}$

$27.3 \pm 3.9^{\star *}$

$5.4 \pm 1.3^{* *}$

$2.7 \pm 2.1^{*}$

$2.0 \pm 5.2^{* * *}$

$150.7 \pm 10.8$

$18.1 \pm 5.4^{* *}$

$312.6 \pm 76.0^{* * *}$

$7.4 \pm 1.4$

$<001$

$45.4 \pm 18.7^{* * *}$

$5.0 \pm 1.8$

$6.1+3.4$

$11.2 \pm 6.2$

Follow-Up

$\mathrm{iHLH}$

101

$79(81.4) \quad<.001$

$77(81.9) \quad 0.420$

$22(23.4) \quad 0.093$

$\begin{array}{ll}22(23.4) & 0.093 \\ 25(27.2) & 0.312\end{array}$

$37(38.1) \quad<.001$

$72(71.3)^{\star \star \star}$

$43(59.7)^{\star * *}$

$16(16.5)$

$56(57.7)^{\star \star \star}$

$12(13.2)^{\star *}$

$12(12.4)^{*}$

$18.1 \pm 7.6^{*}$
$48.9+8.8$

$48.9 \pm 8.8$

$7.7 \pm 6.4$

$50.4 \pm 9.0$
$23.3 \pm 9.0^{* *}$

$23.3 \pm 9.0$
$165.4 \pm 91.8$

$165.4 \pm 91.8$

$14.8 \pm 3.2^{\star * *}$
$23.0 \pm 2.6^{\star * *}$

$27.5 \pm 4.7$

$5.7 \pm 1.4$

$2.7 \pm 2.3^{*}$

$143.3 \pm 16.9^{*}$

$18.2 \pm 5.6$

$281.5+84.2^{*}$

$54.8 \pm 21.7^{* \star *}$

$11.5 \pm 2.4^{\star * \star}$

$<.001$

$<.001$

$<001$

$<.001$

$<.001$

0.684

$<.001$

$<.001$

0.003

0.003

0.044

$<.001$

0.020

$<.001$

0.001

Data are expressed as mean \pm standard deviation for continuous variables or as number (percentage) for binary categorical variables.

Abbreviations: NLH, Normal Luteinising Hormone; HLH, High Luteinising Hormone; CVD, CardioVascular Disease; SF-36, Short-Form 36 Questionnaire; DSST, Digital Symbol Substitution Test; PASE, Physical Activity Scale for the Elderly; PPT, Physical Performance Test; BMI, Body Mass Index; FPG, Fasting Plasma Glucose concentration; HOMA-IR, HOmeostatic Model of Insulin

Resistance; PSA, Prostate Specific Antigen concentration; Hb, Haemoglobin; T, serum Testosterone concentration; SHBG, Sex Hormone Binding Globulin concentration; LH, Luteinising Hormone concentration; FSH, Follicular Stimulating Hormone Concentration

a. $\mathrm{P}$ values were calculated using baseline parameters and either the independent-samples t-test for continuous variables or chi-squared analyses for categorical variables.

b. $\mathrm{P}$ values were calculated using follow-up parameters and either the independent-samples t-test for continuous variables or chi-squared analyses for categorical variables.

c. Educated to less than a degree level

${ }^{*},{ }^{* *},{ }^{* *}$ Data differ significantly $(\mathrm{p}<0.05, p<0.01$ and $\mathrm{p}<0.001$ respectively) from baseline values within the same group when analysed using paired $t$-tests (for continuous variables) or the McNemar test (for categorical variables).

This article is protected by copyright. All rights reserved. 
Table 2. Co-morbidities, Functional Ratings and Elevated Luteinising Hormone

\begin{tabular}{|c|c|c|c|c|c|c|}
\hline \multirow[b]{2}{*}{ Parameter } & \multicolumn{2}{|c|}{ Incident HLH (n=101) } & \multicolumn{2}{|c|}{ Persistent HLH $(n=128)$} & \multicolumn{2}{|c|}{ Recovery from HLH $(n=46)$} \\
\hline & Baseline & Change ${ }^{a}$ & Baseline & Change $^{\mathrm{a}}$ & Baseline & Change $^{a}$ \\
\hline Poor health, $\mathrm{n}(\%)$ & $1.29(0.76,2.18)$ & $1.98(1.01,3.90)^{\star}$ & $1.39(0.86,2.22)$ & $1.60(0.84,3.03)$ & $0.74(0.26,2.09)$ & $0.56(0.13,2.37)$ \\
\hline$\geq 1$ illness, n (\%) & $1.10(0.68,1.78)$ & $1.75(0.92,3.31)$ & $1.76(1.12,2.76)^{\star}$ & $2.02(1.03,3.98)^{*}$ & $0.49(0.21,1.14)$ & $0.52(0.14,1.85)$ \\
\hline$\geq 2$ illnesses, $n(\%)$ & $0.99(0.52,1.86)$ & $1.85(0.84,4.06)$ & $1.85(1.05,3.26)^{\star}$ & $2.09(0.94,4.66)$ & $0.86(0.30,2.48)$ & $0.78(0.07,8.42)$ \\
\hline Diabetes, $\mathrm{n}(\%)$ & $2.62(1.34,5.14)^{\star \star \star \star}$ & $0.35(0.05,2.73)$ & $2.13(1.12,4.08)^{\star}$ & $0.36(0.05,2.81)$ & $0.36(0.07,1.94)$ & $12.75(0.49,332.44)$ \\
\hline CVD, n (\%) & $0.89(0.54,1.46)$ & $2.09(1.12,3.90)^{\star}$ & $1.37(0.88,2.12)$ & $2.58(1.33,5.00)^{\star \star}$ & $0.80(0.33,1.95)$ & $0.92(0.29,2.87)$ \\
\hline Cancer, n (\%) & $0.67(0.20,2.25)$ & $2.77(1.29,5.97)^{\star}$ & $2.06(1.05,4.05)^{\star}$ & $0.88(0.33,2.34)$ & $1.28(0.34,4.76)$ & $1.74(0.33,9.22)$ \\
\hline Prostate disease, n (\%) & $0.27(0.09,0.77)^{\star}$ & $1.18(0.53,2.66)$ & $1.21(0.70,2.09)$ & $0.34(0.10,1.14)$ & $0.52(0.13,2.09)$ & $5.54(0.70,44.16)$ \\
\hline Overall Sexual Function & $-0.03(-0.08,0.02)$ & $-0.02(-0.08,0.04)$ & $-0.02(-0.07,0.02)$ & $-0.00(-0.06,0.06)$ & $0.05(-0.11,0.21)$ & $-0.01(-0.24,0.23)$ \\
\hline SF-36 physical & $0.01(-0.03,0.06)$ & $-0.03(-0.08,0.02)$ & $-0.00(-0.05,0.04)$ & $-0.05(-0.10,0.01)$ & $-0.04(-0.19,0.12)$ & $-0.02(-0.19,0.16)$ \\
\hline $\begin{array}{l}\text { Beck's Depression } \\
\text { Inventory }\end{array}$ & $0.03(-0.01,0.08)$ & $0.03(-0.02,0.09)$ & $0.04(-0.01,0.09)$ & $-0.02(-0.07,0.04)$ & $-0.09(-0.26,0.07)$ & $0.11(-0.06,0.28)$ \\
\hline SF-36 mental & $-0.05(-0.10,-0.00)^{*}$ & $-0.00(-0.05,0.05)$ & $-0.01(-0.06,0.04)$ & $-0.02(-0.08,0.03)$ & $0.03(-0.14,0.19)$ & $0.02(-0.15,0.20)$ \\
\hline DSST & $-0.03(-0.07,0.01)$ & $-0.02(-0.07,0.03)$ & $-0.07(-0.11,-0.02)^{\star \star}$ & $-0.05(-0.10,-0.00)^{\star}$ & $0.08(-0.06,0.21)$ & $0.10(-0.07,0.26)$ \\
\hline PASE score & $-0.03(-0.08,0.01)$ & $0.02(-0.03,0.08)$ & $-0.04(-0.09,0.01)$ & $-0.04(-0.10,0.01)$ & $0.00(-0.15,0.15)$ & $0.04(-0.14,0.23)$ \\
\hline $50-\mathrm{ft}$ walk, seconds & $-0.01(-0.06,0.03)$ & $0.05(0.01,0.10)^{\star}$ & $-0.00(-0.05,0.04)$ & $0.03(-0.01,0.08)$ & $-0.15(-0.30,0.00)$ & $0.10(-0.06,0.27)$ \\
\hline PPT rating & $0.01(-0.04,0.05)$ & $-0.01(-0.06,0.04)$ & $0.00(-0.04,0.05)$ & $-0.09(-0.14,-0.04)^{\star \star}$ & $-0.05(-0.11,0.20)$ & $0.03(-0.14,0.20)$ \\
\hline BMI, $\mathrm{kg} / \mathrm{m}^{2}$ & $-0.01(-0.05,0.04)$ & $-0.01(-0.06,0.04)$ & $-0.04(-0.09,0.01)$ & $0.01(-0.04,0.06)$ & $-0.10(-0.26,0.06)$ & $0.21(0.05,0.36)^{\star}$ \\
\hline HOMA-IR & $0.07(0.02,0.11)^{\star \star}$ & $-0.02(-0.07,0.04)$ & $0.09(0.04,0.14)^{\star \star \star}$ & $0.01(-0.04,0.07)$ & $-0.04(-0.20,0.12)$ & $0.11(-0.07,0.29)$ \\
\hline $\mathrm{Hb}, \mathrm{g} / \mathrm{L}$ & $-0.05(-0.10,-0.00)^{\star}$ & $-0.06(-0.11,-0.01)^{\star}$ & $-0.10(-0.15,-0.05)^{\star \star \star}$ & $0.04(-0.01,0.10)$ & $0.10(-0.07,0.26)$ & $-0.15(-0.33,0.03)$ \\
\hline
\end{tabular}

Data are expressed as odds ratio (95\% confidence interval) for binary categorical variables or as regression co-efficient (95\% confidence interval) for continuous variables.

Data from men with incident or persistent HLH were compared to those from men with persistently normal LH levels. Data from men with recovery from HLH were compared to those from men with persistent HLH. All relationships are adjusted for age, co-morbidity, body mass index, centre, chronic pain, education, smoking, and physical activity.

Abbreviations: HLH, High Luteinising Hormone; CVD, CardioVascular Disease; SF-36, Short-Form 36 Questionnaire; DSST, Digital Symbol Substitution Test; PASE, Physical Activity Scale for the Elderly; PPT, Physical Performance Test; BMI, Body Mass Index; HOMA-IR, HOmeostatic Model of Insulin Resistance; Hb, Haemoglobin.

a. incidence of co-morbidity or percentage change from baseline for functional ratings

${ }^{\star}, p<0.05 ;{ }^{* *}, p<0.01 ;{ }^{* * *}, p<0.00$

This article is protected by copyright. All rights reserved. 


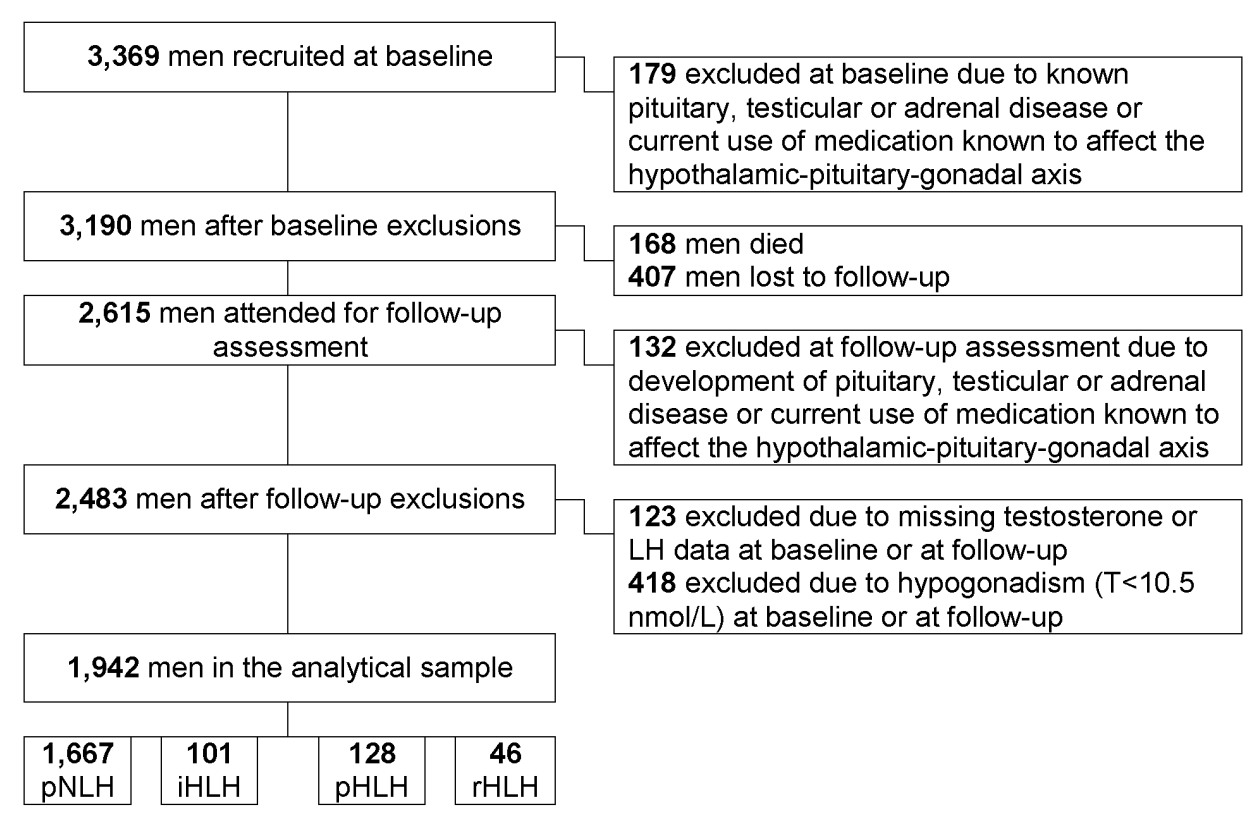

This article is protected by copyright. All rights reserved. 
a)

$p=0.032$

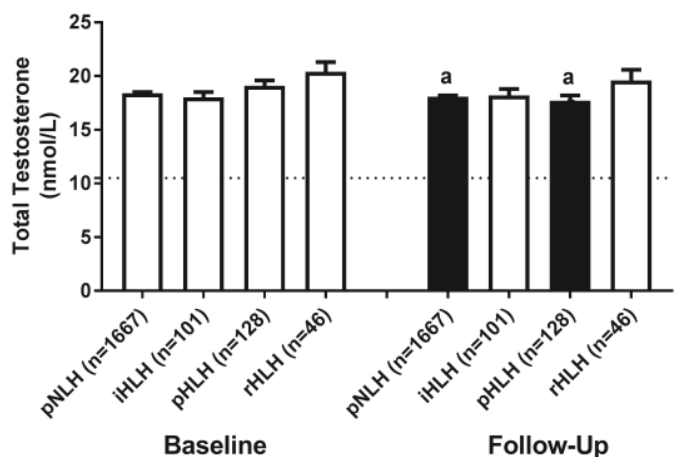

b)

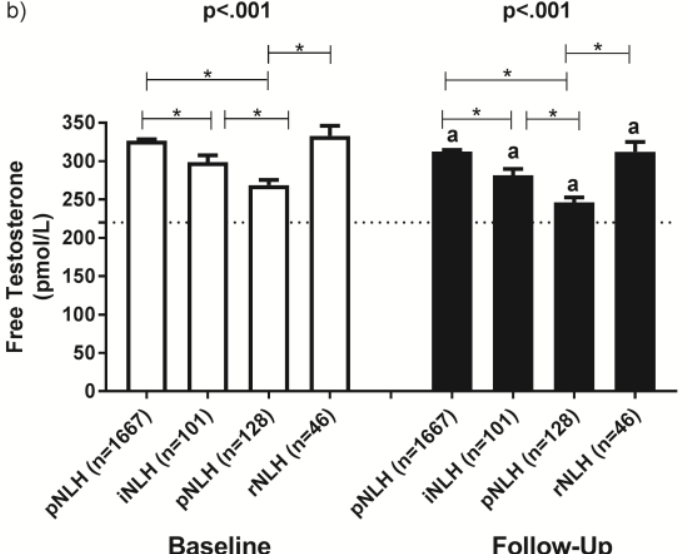

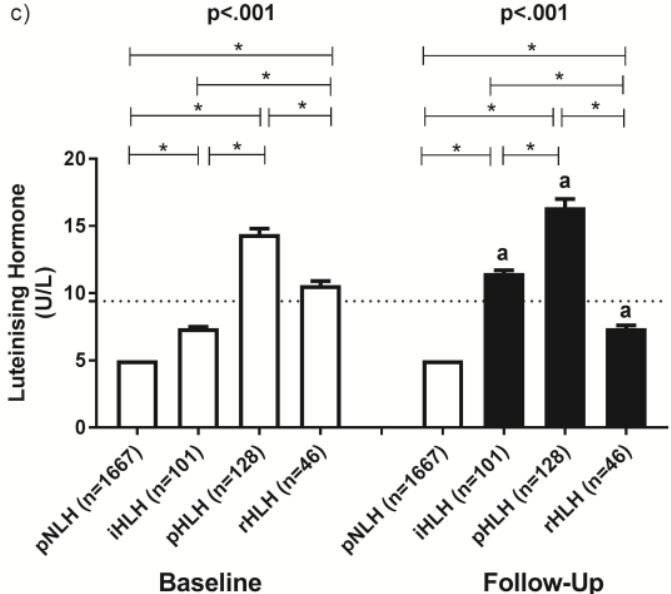

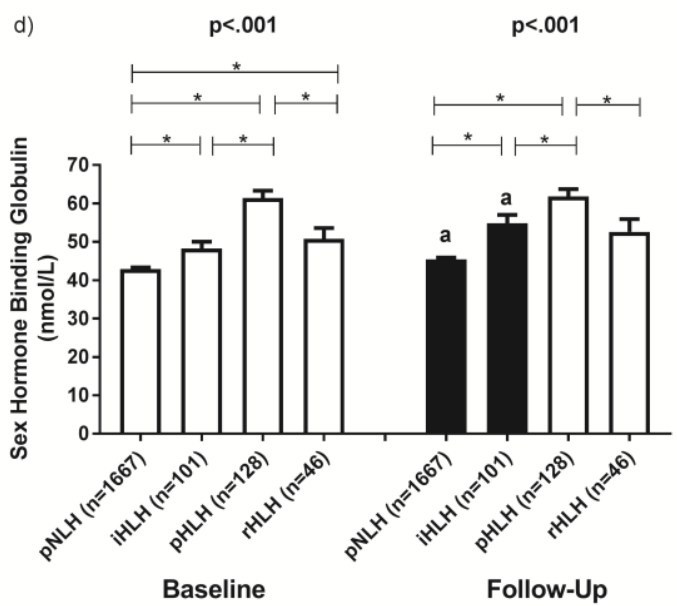

This article is protected by copyright. All rights reserved. 
Incident High Luteinising Hormone - predictors

Age 50-59 years

Age 60-69 years

Age $>70$ years

Diabetes

Overweight

Obese

Chronic pain

Current Smoking

Frequent Alcohol ( $\geq 5 \mathrm{~d} /$ week)

Pre-degree Education

Living with Partner

PASE $\leq 78$

Univariate regression

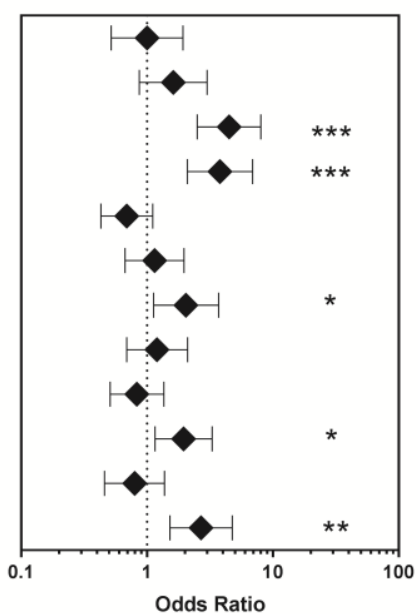

Recovery from High Luteinising Hormone - predictors
Multiple regression

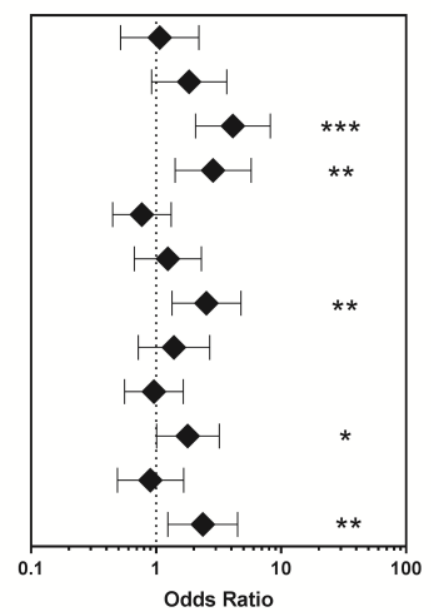

b)

Univariate regression

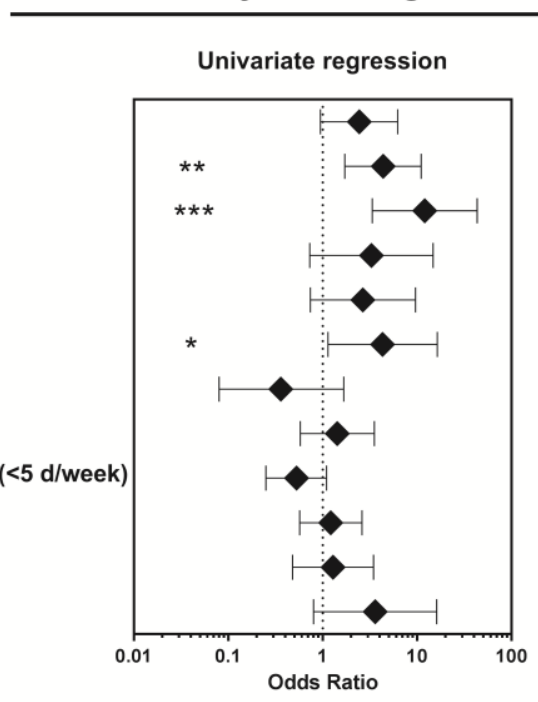

Age 60-69 years Age 50-59 years Age 40-49 years No diabetes Overweight Lean body weight Chronic pain Non-smoking Non-frequent Alcohol intake ( $<5 \mathrm{~d} /$ week) Pre-degree Education Living with Partner PASE $>78$

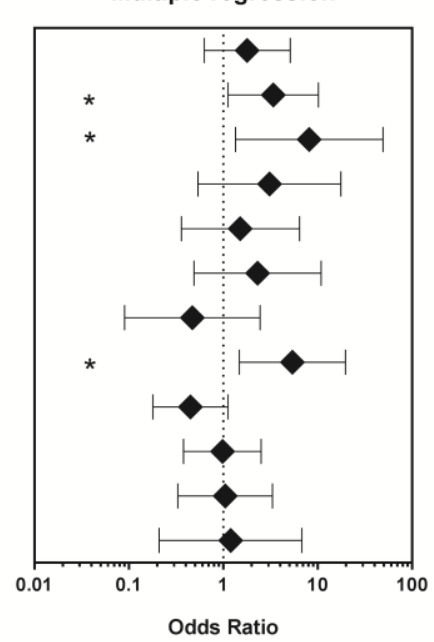

This article is protected by copyright. All rights reserved. 

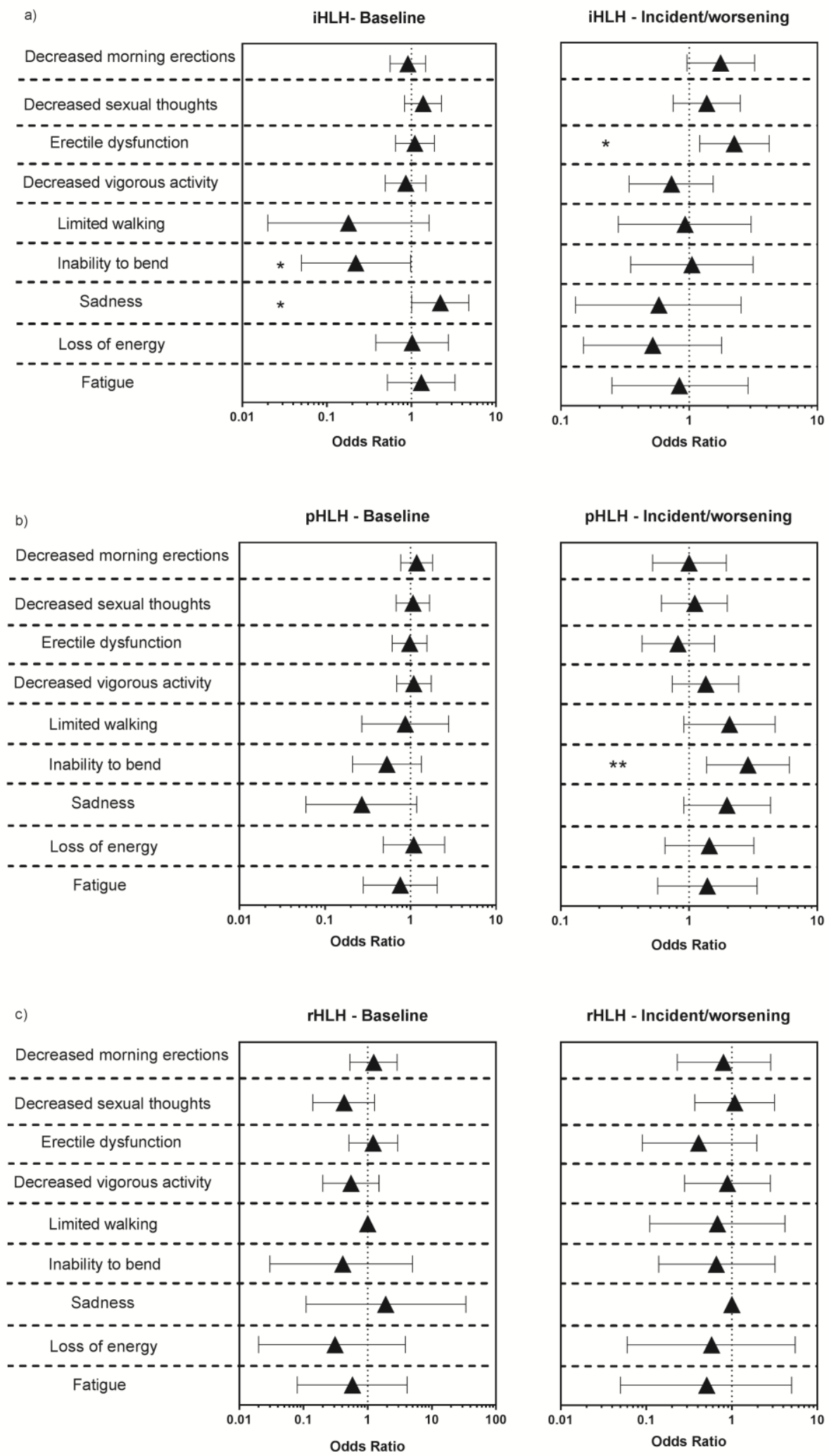

This article is protected by copyright. All rights reserved. 